\title{
Phytochemical analysis and biological activity of a precipitate from Pavetta crassipes
}

\author{
Bello Isaac Asusheyi ${ }^{\star}$, Ndukwe George lloegbulam and Audu Oladimeji Tokumbo \\ Department of Chemistry, Ahmadu Bello University, Zaria, Kaduna State, Nigeria.
}

Accepted 20 May, 2010

\begin{abstract}
Precipitate obtained from the aqueous extract of a Pavetta crassipes K. Schum (Rubiaceae) was analyzed for biological activity and phytochemical makeup. Phytochemical studies of the precipitate showed the presence of flavonoids. Antimicrobial studies showed that the precipitate inhibited the growths of Corynebacterium ulcerans, Escherichia coli and Pseudomonas aeruginosa at $6.25 \mathrm{mg} / \mathrm{ml}$ with corresponding minimum bactericidal concentration (MBC) of $12.5 \mathrm{mg} / \mathrm{ml}$. It also inhibited the growths of Streptococcus pyogenes, Klebsiella pneumoniae and Neiserria gonorrhea at $12.5 \mathrm{mg} / \mathrm{ml}$ with a corresponding $\mathrm{MBC}$ at $25 \mathrm{mg} / \mathrm{ml}$. It however showed no inhibitory effect against Staphylococcus aureus, Bacillus subtilis, Salmonella typhii and Candida albicans. The precipitate is undergoing purification and characterization and will be reported in due course.
\end{abstract}

Key words: Pavetta crassipes, Rubiaceae, flavonoid, antimicrobial screening.

\section{INTRODUCTION}

Plants have a long history of use all over the world for the treatment of different diseases and complaints. In certain African countries, up to $90 \%$ of the population still relies exclusively on plants as a source of medicines and many of these plants have been documented. The available knowledge on the use of plant preparations in traditional medicine is enormous but if this is not rapidly researched, indications as to the usefulness of this vegetable treasure-house will be lost with succeeding generations (Hostettman et al., 2000).

Africa is reputed for the extraordinary richness of its flora, totaling several tens of thousands of species. Environmental degradation provides a threat to biological diversity but the sub-Saharan region still hosts a wide variety of indigenous species. Based on careful observation and a judicious choice of plants, it is possible to discover very new natural products (Hostettman and
Marston, 1990).

Pavetta crassipes K. Schum. (Rubiaceae) is a low glabrous shrub of the savannah with stout sub-quadrangular branches covered with pale corky bark which splits and falls off. In Nigeria, the leaves of this plant are used medicinally in the management of respiratory infections and abdominal disorders. The leaves are also used in Tanzania in the treatment of gonorrhea. In Central Africa, the acid infusion of the leaves is taken as a cough remedy (Watt and Breyer-Brandwijk, 1962). The leaves are eaten by some native tribes pounded up with other food, or boiled in slightly fermented water in which cereals have been left to steep, and mixed with pap. The sap is a coagulant of rubber latex (Dalziel, 1956).

Alkaloid extracts from the plants have been shown to have significant anti-malarial activity (Sanon et al., 2003). The ethanol extract has been shown to lower the blood 
pressures of cats and rats in a dose dependent manner (Amos et al, 1993). In view of this, P. crassipes is a good candidate for screening based on its therapeutic uses. It is imperative that a study of the plant be carried out with a view to justifying the claims by the traditional users and possibly isolating and characterizing the compound(s) responsible for the perceived activity.

\section{MATERIALS AND METHODS}

\section{Plant extraction}

The plant was collected in Zaria in the month of October, 2008 and identified at the Herbarium of the Department of Biological Sciences, Ahmadu Bello University, Zaria, Nigeria as specimen with voucher number $3115.1 \mathrm{~kg}$ of the fresh plant leaves was extracted using hot water and filtered. A yellow precipitate was observed. This was filtered using a Buchner funnel and trap under vacuum. It was dried and weighed and kept in a desiccator until needed.

\section{Phytochemical studies}

Phytochemical analysis was carried out on the precipitate using the method set out by Brain and Turner (1975).

\section{Antimicrobial screening}

The antimicrobial activity was determined using some pathogenic microorganisms. The microorganisms were obtained from the Department of Medical Microbiology, Ahmadu Bello University Teaching Hospital, Zaria, Nigeria. All isolates were checked for purity and maintained in slants of blood agar. A solution of $0.5 \mathrm{~g}$ of the precipitate was made using $10 \mathrm{ml}$ dimethyl sulphoxide (DMSO). This solution was used to check the antimicrobial activities of the precipitate. A control experiment was also set up using DMSO. Blood agar base (Oxoid, England) was prepared according to the manufacturer's instructions. This was then sterilized at $121^{\circ} \mathrm{C}$ for 15 min using an autoclave and was allowed to cool. The sterilized medium $(20 \mathrm{ml})$ was pipetted into sterilized Petri dishes, covered and allowed to cool and solidify. The Petri dishes containing the medium were seeded with the test organisms by the spread plate technique and were left to dry for half an hour. Filter paper discs were cut and sterilized at $160^{\circ} \mathrm{C}$ for $30 \mathrm{~min}$. The sterilized paper discs were then dropped into the solutions of the extracts and were dried at $45^{\circ} \mathrm{C}$. The dried discs were then planted on the medium previously seeded with the test organisms. The plates were incubated at $37^{\circ} \mathrm{C}$ for $24 \mathrm{~h}$ after which they were inspected for the zones of inhibition of growth. The zones were measured and recorded in millimetres by the use of a pair of dividers and a ruler.

\section{Minimum inhibition concentration (MIC)}

Minimum inhibition concentration of the precipitate was carried out on the microorganisms that were susceptible to it and was carried out using the broth dilution method as described by Bauer et al. (1966). Nutrient broth (Oxoid, England) was prepared according to the manufacturer's instructions. $10 \mathrm{ml}$ each was dispensed into 5 sets of screw cap test tubes and sterilized at $121^{\circ} \mathrm{C}$ for $15 \mathrm{~min}$. The test tubes were allowed to cool. McFarland's turbidity standard scale number 0.5 was prepared. $10 \mathrm{ml}$ normal saline was used to make a turbid suspension of the microorganisms. Dilution of the microorganisms was done continuously in the normal saline until the turbidity matched that of the McFarland's scale by visual comparison. At this point the microorganisms had a density of $3 \times$ $10^{8} \mathrm{cfu} / \mathrm{ml}$. Serial dilution of the precipitate was made using the nutrient broth and the following concentrations were obtained; 50, $25,12.5,6.25$ and $3.125 \mathrm{mg} / \mathrm{ml}$. Having obtained the different concentrations, $1 \mathrm{ml}$ of the microorganism in the normal saline was inoculated into the different concentrations of the precipitate in the broth and was incubated at $37^{\circ} \mathrm{C}$ for $24 \mathrm{~h}$. The lowest concentration that showed no turbidity (clear solution) was recorded as the MIC.

\section{Minimum bactericidal/fungicidal concentration (MBC/MFC)}

This was carried out in order to determine whether the microorganisms could be completely killed or their growth could only be inhibited. Blood agar base (Oxoid, England) was prepared according to the manufacturer's instructions. The solution was sterilized at $121^{\circ} \mathrm{C}$ for 15 min using an autoclave and poured into sterilized Petri dishes. The contents of the MIC test tubes in the serial dilution were sub-cultured on the Petri dishes by dipping a sterile wire loop into each test tube and streaked on the surfaces of the Petri dishes. The Petri dishes were incubated at $37^{\circ} \mathrm{C}$ for $24 \mathrm{~h}$ after which they were observed for growth. The minimum bactericidal/fungicidal concentration (MBC/MFC) was the Petri dish with the lowest concentration of the precipitate that had no growth of the micro organisms.

\section{RESULTS AND DISCUSSION}

The phytochemical studies revealed the presence of flavonoids in the precipitate. Flavonoids are widely distributed in plants. They are known to be responsible for the yellow or red/blue pigmentations in flowers and also provide protection from attack by microorganisms and insects. The widespread distribution of flavonoids, their variety and their relatively low toxicity compared to other active plant precipitates (for instance alkaloids) had led to many animals, including humans, ingesting significant quantities in their diet without problems. Flavonoids have been referred to as "nature's biological response modifiers" because of the strong experimental evidence of their inherent ability to modify the body's reaction to allergens, viruses, and carcinogens. They show antiallergic, anti-inflammatory, anti-microbial and anti-cancer activity (Cushnie and Lamb, 2005).

The results of the antimicrobials studies showed that the precipitate had remarkable activity at $50 \mathrm{mg} / \mathrm{ml}$ against six of the ten microorganisms tested with zones of inhibition between 15 to $22 \mathrm{~mm}$. It could not inhibit the growth of Staphylococcus aureus, Bacillus subtilis, Salmonella typhii and Candida albicans. MIC and MBC studies showed that the precipitate inhibited the growths of Streptococcus pyogenes, Klebsiella pneumoniae and Neiserria gonorrhea at concentration of $12.5 \mathrm{mg} / \mathrm{ml}$ with anMBCat $25 \mathrm{mg} / \mathrm{ml}$. Corynebacteriumulcerans, Escherichia 
Table 1. Summary of MIC and MBC of precipitate $(\mathrm{mg} / \mathrm{ml})$.

\begin{tabular}{lcc}
\hline Organism & MIC & MBC \\
\hline Escherichia coli & 6.25 & 12.5 \\
Pseudomonas aeruginosa & 6.25 & 12.5 \\
Streptococcus pyogenes & 12.5 & 25.0 \\
Corynebacterium ulcerans & 6.25 & 12.5 \\
Klebsiella pneumoniae & 12.5 & 25.0 \\
Neiserria gonorrhea & 12.5 & 25.0 \\
\hline
\end{tabular}

coli and Pseudomonas aeruginosa were all inhibited at concentration of $6.25 \mathrm{mg} / \mathrm{ml}$ with corresponding MBC at $12.5 \mathrm{mg} / \mathrm{ml}$ (Table 1).

\section{Conclusion}

The results from this research have supported the ethnomedicinal uses of this plant in the treatment of respiratory infections, abdominal disorders, gonorrhea and as a cough remedy. These diseases can be caused by the respective microorganisms tested. The precipitate is being purified and characterized and in vitro activityrelated studies are on-going to establish the toxicity if any of the precipitate.

\section{REFERENCES}

Amos S, Akah PA, Binda L, Enwerem NM, Ogundaini A, Wambebe C, Hussaini IM, Gamaniel KS (1993). Pharm. Soc. Jap. 26(12):16741680.

Bauer AW, Kirby WMM, Sherris JC, Turk M (1966). Antibiotic susceptibility testing by a standardized single disc method. Am. J. Clin. Pathol. 45:493-496.

Brain KR, Turner TD (1975). The practical evaluation of phytochemicals, Wright Science Technical. Bristol, Britain. pp. 56-64.

Cushnie TPT, Lamb AJ (2005). "Antimicrobial activity of flavonoids". Int. J. Antimicrob. Agents 26(5):343-356.

Dalziel JM (1956). Useful Plants of West Tropical Africa, Crown Agents for Overseas Government: London. P 407.

Hostettmann K, Marston A (1990). In Studies in Natural Products Chemistry. Elsevier. 7:405.

Hostettmann K, Marston A, Ndjoko K, Wolfender JL (2000). The potential of African plants as a source of drugs. Curr. Org. Chem. 4:973-1010.

Sanon S, Azas N, Gasquet M, Ollivier E, Mahiou V, Barro N, CuzinOuattara N, Traore AS, Esposito F, Balansard G, Timon-David P (2003). Antiplasmodial activity of alkaloid extracts from Pavetta crassipes (K. Schum) and Acanthospermum hispidum (DC), two plants used in traditional medicine in Burkina Faso. Parasitol Res. 90(4):314-317.

Watt JM, Breyer-Brandwijk MG (1962). Medicinal and Poisonous Plants of Southern and Eastern Africa, E. and S. Livingstone: Edinburgh. P 901. 